\title{
Welcome to the 13th Volume of Immunotherapy
}

\author{
Ebony Torrington*, 1 (iD) \\ ${ }^{1}$ Future Science Group, Unitec House, 2 Albert Place, Finchley, London N3 1QB, UK \\ *Author for correspondence: e.torrington@futuremedicine.com
}

'In Volume 12, we published a large number of high-impact and insightful articles across a diverse range of topics within this ever-evolving field. Our top five most read articles address the COVID-19 pandemic."

First draft submitted: 19 November 2020; Accepted for publication: 20 November 2020; Published online: 7 December 2020

Keywords: altmetrics $\bullet$ COVID-19 • immunotherapy • readership • social media • top content

\section{Background}

To all our readers, we would like to wish you a very Happy New Year and are pleased to welcome you to Volume 13 of Immunotherapy.

In this Foreword, I will highlight articles from Immunotherapy published in 2020 that signify the progress made in the field. In 2020 we received a number of submissions addressing COVID-19, from therapeutic strategies to treat people infected with the virus, to protecting vulnerable, immunosuppressed populations of people.

A variety of manuscripts will be featured in this Foreword, from Case Reports and Reviews to Editorials and Commentaries, covering a range of research and opinions published in Immunotherapy in 2020.

\section{Content highlights}

In Volume 12, we published a large number of high-impact and insightful articles across a diverse range of topics within this ever-evolving field. Our top five most read articles address the COVID-19 pandemic. Table 1 details the five most-read articles published in Immunotherapy in 2020. At the time of writing (November 2020), our most read article of 2020, and one of the most read articles across Future Medicine, was a Commentary titled 'Controversies about COVID-19 and anticancer treatment with immune checkpoint inhibitors' [1]. This article also happened to be one of our top scoring articles on Altmetric and has already been referenced in many other papers published last year. In this opinion piece, M Bersanelli from University Hospital of Parma (Italy) discussed the impact that COVID-19 could have on people with cancer who are receiving immune checkpoint inhibitor treatment.

In our most read Research Article by JM Díez et al. the authors tested Gamunex ${ }^{\circledR}-\mathrm{C}$ and Flebogamma ${ }^{\circledR}$ DIF intravenous immunoglobulins using ELISA techniques and found the immunoglobulins contained antibodies reacting against SARS-CoV-2 antigens [2]. The authors suggested that these intravenous immunoglobulins could be used for COVID-19 management, however, further studies would be required to determine this.

In another highly read Commentary, 'COVID-19: the use of immunotherapy in metastatic lung cancer', the authors discuss the challenges COVID-19 poses on people with lung cancer receiving immunotherapy treatment, due to the increased risk that the treatment may expose patients to [3].

In the Editorial entitled: 'Do checkpoint inhibitors compromise the cancer patients' immunity and increase the vulnerability to COVID-19 infection?', the authors discuss immune response in people with cancer who are treated with immune checkpoint inhibitors and how these people could be at a higher risk of infection with SARS-CoV-2 [4].

Throughout 2020, we saw an urgency to find treatment for infection with SARS-CoV-2 and some of those therapeutic solutions have been immunotherapy-based. My final pick of our most read content in 2020, is a highly read Case Report titled 'Recovery of COVID-19 acute respiratory distress syndrome with tocilizumab: successful outcome in two critically ill patients' [5]. Here, the authors presented two cases of tocilizumab administration in 


\begin{tabular}{|c|c|c|c|c|}
\hline Rank & Title & Authors & Volume (Issue) & Ref. \\
\hline 1 & $\begin{array}{l}\text { Controversies about COVID-19 and anticancer treatment with immune checkpoint } \\
\text { inhibitors }\end{array}$ & Bersanelli M & 12 (Issue 5) & [1] \\
\hline 2 & $\begin{array}{l}\text { Currently available intravenous immunoglobulin contains antibodies reacting } \\
\text { against SARS coronavirus } 2 \text { antigens }\end{array}$ & Díez JM, Romero C \& Gajardo R & 12 (Issue 8 ) & [2] \\
\hline 3 & COVID-19: the use of immunotherapy in metastatic lung cancer & $\begin{array}{l}\text { Davis A P, Boyer M, Lee J H \& Kao } \\
\text { S C }\end{array}$ & 12 (Issue 8) & [3] \\
\hline 4 & $\begin{array}{l}\text { Do checkpoint inhibitors compromise the cancer patients' immunity and increase } \\
\text { the vulnerability to COVID-19 infection? }\end{array}$ & Kattan J, Kattan C \& Assi T & 12 (Issue 6) & [4] \\
\hline 5 & $\begin{array}{l}\text { Recovery of COVID-19 acute respiratory distress syndrome with tocilizumab: } \\
\text { successful outcome in two critically ill patients }\end{array}$ & $\begin{array}{l}\text { Cala-García JD, Sierra-Bretón JD, } \\
\text { Cavelier-Baiz J E, Faccini-Martínez } \\
\text { AA \& Pérez-Díaz CE }\end{array}$ & 12 (Issue 5) & [5] \\
\hline
\end{tabular}

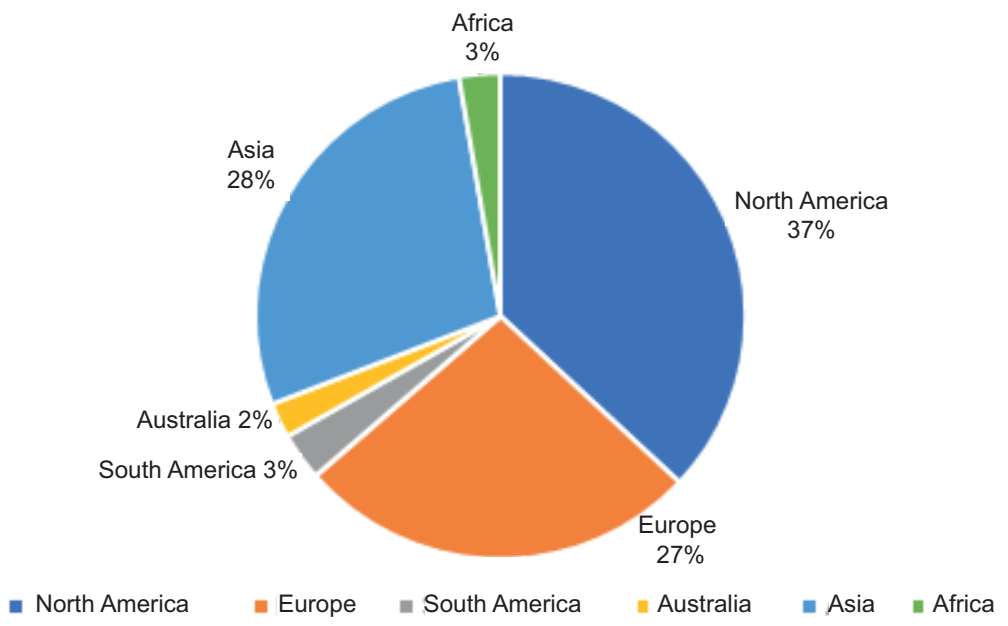

Figure 1. Readership demographics in $\mathbf{2 0 2 0}$ for Immunotherapy.

people who were critically ill with COVID-19, finding the therapy effective in COVID-19-associated cytokine storm syndrome. The authors suggested that further clinical tests were needed to establish the safety and effectiveness in a larger population of people.

Immunotherapy on Altmetric in 2020

Altmetric is a helpful tool we use to measure the impact of our publications. It collates information from various online sources on different platforms, such as twitter, news outlets and Mendeley, to show the way in which the research is being broadcast across the world.

Special mention goes to a review titled 'Sublingual immunotherapy for food allergy and its future directions,' which gained social media attention and was picked up by multiple news outlets, leading to the review achieving the journal's highest Altmetric score in 2020 [6]. The article discusses the mechanisms of sublingual immunotherapy, early studies of the therapy used to treat food allergy, and larger randomized controlled trials for treatment of peanut allergy. We look forward to continuing our successful partnership with Altmetric into 2021.

\section{Readership demographics}

In 2020, our content was most read by experts in North America (37\%) and Asia (28\%), followed closely by experts in Europe (27\%) (Figure 1). With the importance of the field and number of breakthroughs continuing to rise, we look forward to seeing the global reach of Immunotherapy grow even further in the coming year. 


\section{Social media}

Immunotherapy encourages our readers to follow us on Twitter (@fsgimt) [7], where we discuss the latest news surrounding immunotherapy, journal highlights and newly published articles. This allows us to engage directly with our readers along with experts in the field.

\section{Conclusion}

As with the previous years, we welcome any feedback from our readers, whether that be key topics that you feel should be covered or where you see the field going in the future. We welcome unsolicited research, review and opinion article proposals and would be delighted to hear from you if you are interested in submitting to the journal.

I would like to also take this opportunity to thank our readers, esteemed Editorial Board, peer reviewers and contributing authors for their continued support. We very much look forward to collaborating with you all in 2021 and hope to see Immunotherapy progress even more in the coming year.

\section{Financial \& competing interests disclosure}

E Torrington is an employee of Future Medicine Ltd. The author has no other relevant affiliations or financial involvement with any organization or entity with a financial interest in or financial conflict with the subject matter or materials discussed in the manuscript apart from those disclosed.

No writing assistance was utilized in the production of this manuscript.

\section{References}

1. Bersanelli M. Controversies about COVID-19 and anticancer treatment with immune checkpoint inhibitors. Immunotherapy 12(5), 269-273 (2020).

2. Díez JM, Romero C, Gajardo R. Currently available intravenous immunoglobulin contains antibodies reacting against severe acute respiratory syndrome coronavirus 2 antigens. Immunotherapy 12(8), 571-576 (2020).

3. Davis AP, Boyer M, Lee JH, Kao SC. COVID-19: the use of immunotherapy in metastatic lung cancer. Immunotherapy 12(8), 545-548 (2020).

4. Kattan J, Kattan C, Assi T. Do checkpoint inhibitors compromise the cancer patients' immunity and increase the vulnerability to COVID-19 infection? Immunotherapy 12(6), 351-361 (2020).

5. Cala-García JD, Sierra-Bretón JD, Cavelier-Baiz JE, Faccini-Martínez AA, Pérez-Díaz CE. Recovery of COVID-19 acute respiratory distress syndrome with tocilizumab: successful outcome in two critically ill patients. Immunotherapy 12(5), 1127-1123 (2020).

6. Schworer SA, Kim EH. Sublingual immunotherapy for food allergy and its future directions. Immunotherapy 12(12), 921-931 (2020).

7. Twitter. Immunotherapy journal (@fsgimt) (2020). https://twitter.com/fsgimt 
